\title{
Assessment of Socio-Economic and Agronomic Characteristics Influencing Variety Choice in Rice Based Farming System in Fogera- Ethiopia
}

\author{
Tegegne, Misganaw (M.S.c) ${ }^{1^{*}}$, Dr. Mathias Becker ${ }^{2}$ \\ ${ }^{I}$ Fogera National Rice Research and Training Center-Ethiopian Institute of Agricultural Research, Woreta- \\ Ethiopia \\ ${ }^{2}$ Professor, University of Bonn, Germany
}

*Corresponding Author: Tegegne, Misganaw (M.S.c), Fogera National Rice Research and Training Center-Ethiopian Institute of Agricultural Research, Woreta- Ethiopia

\begin{abstract}
An exploratory study was conducted in Fogera - Ethiopia, with the aim of assessing socioeconomic and agronomic characteristics of small-holder rice producing systems at present and in the past (baseline around 2008). Special emphasis was given to the interaction between farm characteristics and the choice of varieties. Three peasant associations ("Kebeles") were selected and a total of 120 rice-producing households (40 per Kebele) were considered for the survey. Although many varieties are known by farmers and development agents, mainly two are actuallyavailable in the market: X.Jigina (the very first rice variety introduced to Fogera and unregistered one) while Gumara which is an improved variety. Despite yield stagnation and increasing phytosanitary problems, all interviewed farmers still cultivated X.Jigina. Very few farmers cultivated Gumara at the same time. X. Jigina was the dominant variety both in terms of seed supply and market demand. X.Jigina is highly acceptable at the market due to white in color and good cooking quality.X.Jigina variety has become gradually infested by diseases and pests, then farmers started looking for other new and improved varieties such as Shaga, Wanzaye, Gumara etc. Although these varieties are better in terms of yield, biomass, and disease resistance, however color issue which is important for the farmers not yet sufficiently addressed. The research and development sectors should focus on addressing market preferences, which are related to white grain color and the suitability of the new/improved varieties to be used as prime mater to prepare "Injeera" and other food recipes such as "Tela", "Areki", "Kinche" etc. Multiplication and provision of improved varieties particularly recently released (Shaga, Wanzaye, Ereb and Abay) must be addressed to overcome rice yield stagnation in Fogera. The respective breeding research team needs to focus on improvement of variety that will address the issues of color and cooking quality.
\end{abstract}

Keywords: Grain color, Gumara, Market, Oryza sativa, X.Jigina

\section{INTRODUCTION}

\subsection{Rice in Ethiopia}

In the early 1970s Ethiopia was hit by a severe famine which took the lives of hundreds of thousands of human beings (estimations range from 250,000 to 750,000 people) and countless domestic animals (Kebede, 1988). As a response to this dramatic event and aiming at the long-term enhancement of food security, the North Korean development cooperation introduced rice cultivation in Ethiopia, first in the Fogera and Gambella Plains(Belayineh et al. 2017). From then on rice cultivation, mostly undertaken by small-scale farmers, has expanded to several plains and wetlands nationwide(Alemu et al. 2011)

In the country, the demand for rice consumption is increasing as rice is used for different purposes and food types(Temesgen et al 2014). It is compatible with various traditional food recipes like Injera (traditional Ethiopian bread), and local beverages (like "tela" and "areki"). While Ethiopia's annual rice production increased, it still does not satisfy the growing internal market demand (Takele, et al 2017). To meet the increasing demand for rice in the local market, farmers from small to large scale have started acquiring land and developing new rice farms in different parts of the country(Temesgen et al. 2014) . 


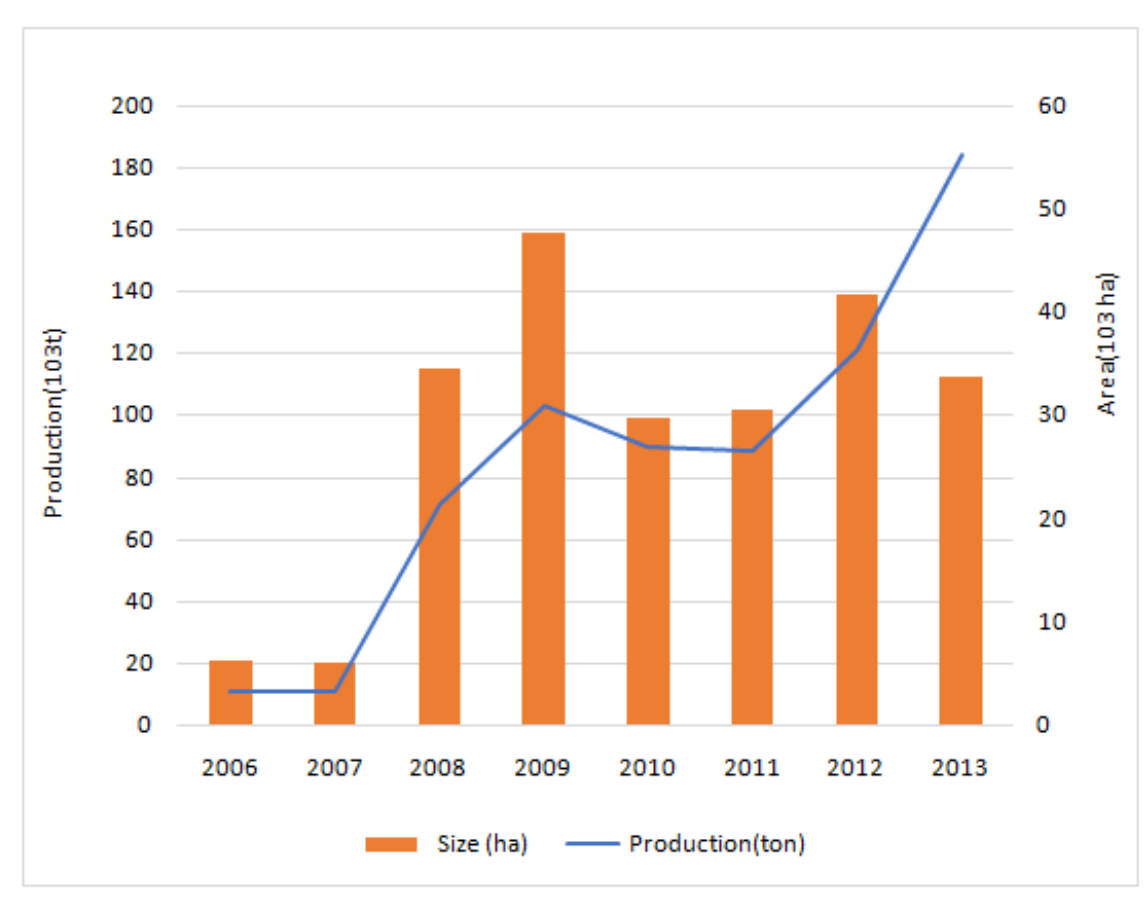

Figure1. Rice production trend in Ethiopia (Source: FAOSTAT, 2018)

Recent studies focusing on determinants of adoption of improved upland(Asmelash 2014)and lowland (Hagos 2015) rice varieties in Fogera suggest socio-economic factors such as distance of household to market and presence of extension agents among others as highly influencing factors for the adoption of new varieties. However the mentioned studies have not assessed either agronomic aspects of the system nor organoleptic properties of the improved varieties. Furthermore, the author of the present thesis is not aware of any report in the scientific literature assessing the agronomic and farm related socio-economic evolution of the rice cultivation systems in Fogera, from the beginning of rice introduction in the 70's until the present. Responding to the current knowledge gap this study aimed at assessing the lowland rice production systems in Fogera by taking into consideration of both agronomic and socio-economic characteristics of the rice producing households.

\section{HYPOTHESIS AND OBJECTIVES}

Under the assumption that the characterization of transformation patterns in rice cultivation in Fogera is possible, the present study sets out to assess the interaction of socioeconomic and agronomic characteristics of the rice cultivation systems in Fogera and their role on the development pathways of rice cultivation. A thorough socioeconomic and agronomic characterization of the rice based systems in Fogera might offer a deeper insight in the dynamics of rice variety choice by smallholder farmers.

For this purpose the main objective of the study is:

To assess the socio-economic and agronomic characteristics of the rice production systems in the region and changes in the last 10 years.

Accordingly, the specific objectives are:

- To assess the structure and development of rice cultivation systems in Fogera

- To assess and identify main influencing factors in relation with rice variety choice by farmers.

- To assess the status of rice consumption and types of food prepared from rice in rice producing households.

\section{Methodology}

\subsection{Study Site}

Fogera is located in Amhara region in the North West of Ethiopia situated between the latitudes $11^{\circ} 57$ and $11^{\circ} 59$ and the longitudes $37^{\circ} 42$ and $37^{\circ} 43$ and altitudes ranging between 1793 to 1800 meters above sea level. Its mean annual rainfall is $1216 \mathrm{~mm}$ ranging from 1103-1336 presenting a dry season 
(March and April) and a long rainy season (June to September) (Gebey 2012) . Fogera is one of the 106 districts (local name - Woreda) of the Amhara Regional State, located in the South Gondar Zone. Woreta is the capital of the district and is found $625 \mathrm{~km}$ from Addis Ababa and $55 \mathrm{~km}$ from the Regional capital city, Bahir Dar.

Fogera is bordered by Libo Kemkem district in the North, Dera district in the South, Lake Tana in the West and Farta district in the East. The district is divided into 34 kebels (local name for Peasant Association - PA): 29 rural and 5 urban kebeles. The rural population is estimated to be around 220 000 and the number of agricultural households is approximately 44000(Hagos 2015). The district is dominantly known by rice production besides maize, finger millet, tef, onion, cattle rearing, etc.

Farmers largely depend on the long rainy season for crop production and rice cultivation is exclusively undertaken in the period from June to September taking advantage of the flood water coming from two sources: the overflow of water from Lake Tana due to the heavy rains and the contribution of tributary rivers Eribb and Gumara.Rice cultivation is followed by different crops such as onion, tef and other upland crops in the dry season.

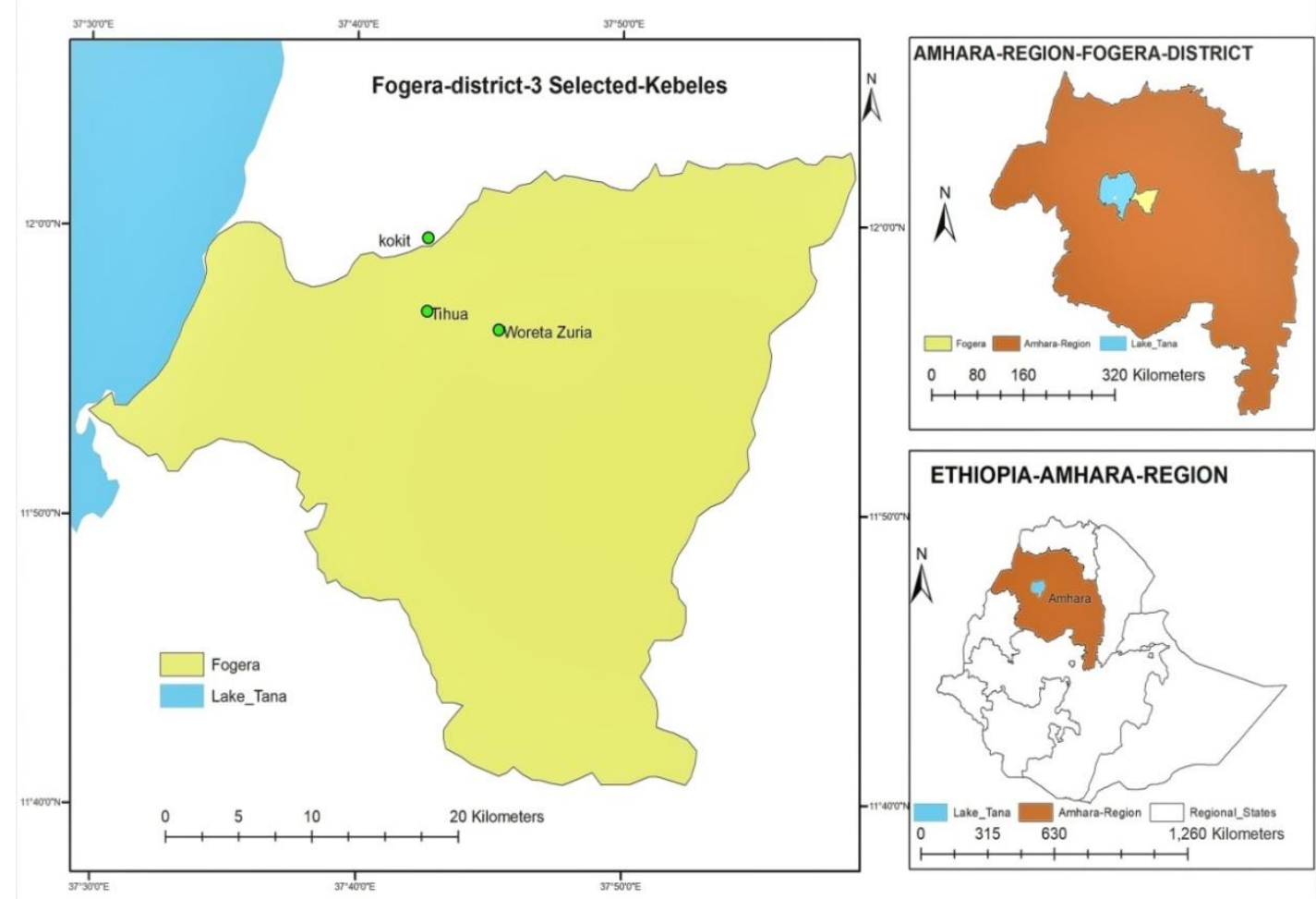

Figure2. Location of the study area (Fogera) and selected peasant associations (own ArcGIS result, 2018)

\subsection{Survey Design and Sampling Techniques}

The study targeted smallholder rice producing farmers in the Fogera district, a location with high potential for rice production in the country. Three kebeles (peasant associations)were selected: namely Kokit, Tihua and Woreta Zuria (see Fig. 1). The choice of these three kebeles was based on their proximity to the main road and accessibility to public transportation services. Thus, it was more time effective for the field work to assess households with relatively good access to roads. Proportional sampling procedures with respect to population size or sampling frame were not undertaken due to unavailability of actual recorded data of the number of rice producing farmers. An equal sample size of $n=40$ was determined in each kebele resulting in a total of $n=120$ respondents in the study area.

\subsection{Data Collection and Data Types}

In the assessment work both primary and secondary sources of data were considered. Primary data were collected directly from rice producing households by using a structured survey tool, an information acquisition support form (IASF) which was pre-tested before entering into the survey 
activities. During the survey the IASF was adapted according to the reality of the rice production system in the study area. Secondary support and validation data were collected from the Fogera research center, the district level agricultural and rural development office, the administrative office of each "kebeles" and from extension workers. Both continuous and categorical data were collected related to socioeconomic and agronomic variables.

\subsection{Statistical Analysis}

Descriptive and central statistics were used for characterization and description of the rice farming households. Inferential statistics were as well applied to test statistical differences on empirical distributions of variables between groups. T-test and chi-square test were used depending on the nature of the variables (continuous and categorical variables).

\section{Results}

\subsection{Characterization of Fogera Rice Based System and Changes}

\subsubsection{General characterization}

Out of 120 farmers considered in the survey, $80 \%$ of respondents were male house hold heads. The mean age for rice producing farmers was approximately 41 years ranging from 20 to 73 years. More than half $(54 \%)$ of farmers were less than 40 years old averaging 29 years. Concerning educational status, only $35 \%$ of farmers were literate. Most did not attend formal education. The mean family size of the considered rice producing households was 5 persons from which in average 3 members might be involved in agriculture.

\subsubsection{Reasons of Variety Choice by Farmers}

Farmers were asked to express three main reasons influencing their variety preference. The most common reasons mentioned were: grain color, market acceptance and cooking quality. Out of 120 farmers $78 \%$ of them chose grain color (white) as the first reason to prefer X.Jigna. On the other hand the $44 \%$ of the farmers categorized market acceptance under the second reason to prefer X.Jigina. None of farmers mentioned cooking quality as first variety criteria, however, $32 \%$ respondent farmers stated cooking quality as their second reason and $60 \%$ expressed cooking quality as the third reason for choosing X.Jigna (see table 2.)

Table2. Variety choice reasons by farmers.

\begin{tabular}{|c|c|c|c|c|c|}
\hline \multirow[t]{2}{*}{ Preference reasons } & \multicolumn{5}{|c|}{ Category of choice } \\
\hline & $1^{\text {st }}$ & $2^{\text {nd }}$ & $3^{\text {rd }}$ & $4^{\text {th }}$ & $5^{\text {th }}$ \\
\hline & $\%(n)$ & $\%(n)$ & $\%(n)$ & $\%(n)$ & $\%(n)$ \\
\hline Grain color & $78.3(94)$ & $17.5(21)$ & $3.3(4)$ & $0(0)$ & $0(0)$ \\
\hline Market & $21.7(26)$ & $44.2(53)$ & $27.5(33)$ & $0.8(1)$ & $4.2(5)$ \\
\hline Cooking quality & $0(0)$ & $32.5(39)$ & $60.8(73)$ & $3.3(4)$ & $0(0)$ \\
\hline Grain size & $0(0)$ & $4.2(5)$ & $4.2(5)$ & $34.2(41)$ & $20.8(25)$ \\
\hline Milling quality & $0(0)$ & $0(0)$ & $0(0)$ & $25(30)$ & $37.5(45)$ \\
\hline No $1^{\text {st }}, 2^{\text {nd }}, 3^{\text {rd }}, 4^{\text {th }}, 5^{\text {th }}$ reason & $0(0)$ & $1.7(2)$ & $4.2(5)$ & $36.7(44)$ & $37.5(45)$ \\
\hline Total & $100(120)$ & $100(120)$ & $100(120)$ & $100(120)$ & $100(120)$ \\
\hline
\end{tabular}

\subsubsection{Rice Consumption}

Rice has become an ingredient used daily for food elaboration in all considered rice producing households in Fogera. The first most important and common type of food prepared from rice is "Injeera"*. Second and third more commonly prepared types of food using rice are "Dabo" and "kinche" respectively. "Injeera" is a typical Ethiopian soft bread served with nearly all kind of dishes. "Dabo" is a traditional dry bread usually eaten as special dish for festive days. "Kinche" is a cooked rice.

*Rice producing households in Fogera usually prepared Injeera not exclusively from rice rather they mix its flour with other crops like tef, maize or finger millet. Other types of food prepared using rice include porridge and infrequently soup (see table 3 ). The average consumption per rice producing household is $84 \mathrm{~kg}$ monthly and the maximum is $200 \mathrm{~kg}$ while $20 \mathrm{~kg}$ is the minimum consumption. 
Assessment of Socio-Economic and Agronomic Characteristics Influencing Variety Choice in Rice Based Farming System in Fogera- Ethiopia

Table3. Types of food prepared from rice by households in ranking order.

\begin{tabular}{|c|c|c|c|}
\hline Types of food & \multicolumn{3}{|c|}{ Proportion } \\
\hline & $1^{\text {st }}$ important & $2^{\text {nd }}$ important & $3^{\text {rd }}$ important \\
\hline & $\%(\mathbf{n})$ & $\%(\mathbf{n})$ & $0(0)$ \\
\hline Injeera & $100(120)$ & $0(0)$ & $18.3(22)$ \\
\hline Bread(“Dabo") & $0(0)$ & $50.8(61)$ & $34.2(41)$ \\
\hline Kinche & $0(0)$ & $25(30)$ & $33.3(40)$ \\
\hline Porridge & $0(0)$ & $23.3(28)$ & $14.2(17)$ \\
\hline No $1^{\text {st }}, 2^{\text {nd }}, 3^{\text {rd }}$ food & $0(0)$ & $0.8(1)$ & $\mathbf{1 0 0}(\mathbf{1 2 0})$ \\
\hline Total & $\mathbf{1 0 0}(\mathbf{1 2 0})$ & $\mathbf{1 0 0}(\mathbf{1 2 0})$ & \\
\hline
\end{tabular}

\subsubsection{Changing Aspects of Cultivated Rice Farm ( In The Last 10 Years)}

A total of 81 ha (120 farmers) were covered by rice in the study area 10 years ago. At present, the same number of farmers cultivates 99 ha of rice. The total gross increase in rice area was 23 ha undertaken by 42 farmers, accounting for $35 \%$ of the respondents. Only 6 famers (5\%) reduced their cultivated area by 4 ha. Therefore, the net increase was 18.3 ha in the last ten years. More than half of the respondents $(60 \%)$ didn't change the size of their rice farm in the last ten years.

The average cultivated rice farm per rice producer in Fogera today is 0.83 ha, whereas it was 0.67 ha ten years ago. This indicates there was an increasing trend of land allocation for rice production over the las ten years in the study area (Fogera).

In the past 31 farmers (26\%) did not cultivate rice, whereas in the present the minimum cultivated rice area per farm is 0.25 ha. The maximum cultivated area is/was 3 ha for both the present and the past.

Table4. Cultivated rice farm in the present and ten years ago.

\begin{tabular}{|l|l|l|}
\hline Cultivatedrice (ha) & Past (10 years ago) & Present \\
\hline Mean & 0.67 & 0.83 \\
\hline Minimum & 0.00 & 0.25 \\
\hline Maximum & 3 & 3 \\
\hline Median & 0.65 & 0.75 \\
\hline
\end{tabular}

\subsubsection{Seed Establishment}

Regarding method of crop establishment, in the past $83 \%$ of farmers used broadcasting as establishment method and the rest applied row planting. On the other hand, in the present $60 \%$ of farmers practice seed broadcasting, $19 \%$ apply row planting and $21 \%$ use both methods. These numbers point out at broadcasting as the prevalent establishment method in the region.

\subsubsection{Types of Rice Varieties Used by Farmers}

Ten years ago, all rice producing farmers cultivated the variety X.Jigina. As well, in the present all farmers cultivated X.Jigina, however, a very small proportion of them (10 farmers, 8.33\%) cultivated both in parallel X.Jigina and Gumera. There was no exclusive cultivation of Gumara.

\subsubsection{Trends of Fertilizer Application}

In the past farmers did not apply any kind of chemical fertilizer. In the present all farmers apply nitrogen based fertilizer and up to 65\% of the farmers apply phosphorous based fertilizer. Fertilizer is applied to the rice field at different stages of growth either two or three times depending on the availability of fertilizer in the district. They use both DAP and UREA.

\subsubsection{Socioeconomic and Demographic Characteristics}

The dataset was divided into two groups, the farmers cultivating exclusively X.Jigina $(n=110)$ and the farmers cultivating both, X.Jigina and Gumara $(n=10)$. The result of the $t$-test applied to continuous variables (see Table 5) indicated that distance to market, distance to extension agent, distance to main road and total own land holdings are significantly different between the two groups. 
Assessment of Socio-Economic and Agronomic Characteristics Influencing Variety Choice in Rice Based Farming System in Fogera- Ethiopia

Table5. T- test of continuous variables between partial users of Gumaraand exclusive users of X-Jigina.

\begin{tabular}{|c|c|c|cc|}
\hline Continuous variables & $\begin{array}{c}\text { X.Jigina user } \\
(\mathrm{n}=110)\end{array}$ & $\begin{array}{c}\text { Gumarauser } \\
\mathrm{n}=(10)\end{array}$ & $\begin{array}{c}\text { t-test } \\
\mathrm{t} \text {-value }\end{array}$ & $\mathrm{p}$-value \\
\hline Age of HH head (years) & 41 & 40 & 0.125 & 0.901 \\
\hline Distance to extension agent (km) & 2.42 & 0.90 & 2.106 & $0.037^{* *}$ \\
\hline Distance to main road access (km) & 1.12 & 0.41 & 2.012 & $0.047^{* *}$ \\
\hline Distance to market (km) & 4.33 & 6.30 & -2.823 & $0.006^{* * *}$ \\
\hline Years of rice farming experience (years) & 12.6 & 13.8 & -0.676 & 0.501 \\
\hline Total size of own land holdings (ha) & 1.162 & 1.675 & -2.314 & $0.022^{* *}$ \\
\hline Rice home consumption per month (kg) & 82.59 & 99.00 & -1.318 & 0.190 \\
\hline Family member involved in agriculture (no) & 3 & 4 & -0.811 & 0.419 \\
\hline
\end{tabular}

$* * * * * * 1,5,10 \%$ level of significance, respectively

For categorical variables, chi-square test was applied to test whether each of the variables is significantly different between groups. Off farm income, membership to agricultural cooperatives and participation in field day are significantly different between the groups (Table 6).

Table6. Categorical variables and chi-square test between partial users and non-partial users.

\begin{tabular}{|c|c|c|c|c|}
\hline Categorical variables & \multicolumn{2}{|c|}{$\begin{array}{c}\text { Gumara(partial)user X.Jigina user } \\
\text { Percentage proportion }\end{array}$} & $C h i$-square $\left(\mathrm{x}^{2}\right)$ & p-value \\
\hline \multicolumn{3}{|l|}{ Gender } & \multirow{3}{*}{0.087} & \multirow{3}{*}{0.768} \\
\hline male & 6.7 & 76.7 & & \\
\hline female & 1.7 & 15.0 & & \\
\hline \multicolumn{3}{|l|}{ Education } & \multirow{3}{*}{0.082} & \multirow{3}{*}{0.774} \\
\hline literate & 3.3 & 32.5 & & \\
\hline Illiterate & 5 & 59.2 & & \\
\hline \multicolumn{3}{|l|}{ Off farm income } & \multirow{3}{*}{9.545} & \multirow{3}{*}{$0.002 * * *$} \\
\hline yes & 2.5 & 4.2 & & \\
\hline no & 5.8 & 87.5 & & \\
\hline \multicolumn{3}{|l|}{ Membership to co-op } & \multirow{3}{*}{5.779} & \multirow{3}{*}{$0.016^{* *}$} \\
\hline yes & 3.3 & 69.2 & & \\
\hline no & 5.0 & 22.5 & & \\
\hline \multicolumn{3}{|l|}{ Access to radio or tv } & \multirow{3}{*}{2.430} & \multirow{3}{*}{0.119} \\
\hline yes & 3.3 & 17.5 & & \\
\hline no & 5 & 74.2 & & \\
\hline \multicolumn{3}{|l|}{ Participation in field day } & \multirow{3}{*}{8.727} & \multirow{3}{*}{$0.003 * * *$} \\
\hline yes & 4.2 & 12.5 & & \\
\hline no & 4.2 & 79.2 & & \\
\hline
\end{tabular}

$*_{* * *, * *,}, 1,5,10 \%$ level of significance respectively

\section{DISCUSSION}

\subsection{Characterization of Fogera Rice Based System and Changes}

\subsubsection{Gender and Age}

In the study area (Fogera) female farmers did not seem to be engaged in rice production. In general terms very rarely female farmers are involved in agricultural activities /or responsible in the household to take decisions regarding agri-business. Specifically in the case of our sampled, a woman was practically "forced" to become head of the agricultural household whether because she divorced, or her husband passed away. Even in the case, that a woman is the decision maker in the household, nearly all agricultural activities are undertaken by the male family members involved in agriculture especially teenagers, when they are old enough to do agricultural business.

Currently, many young farmers are attracted and engaged in rice sector in Fogera as the crop has become more profitable compared to other crops. One young farmer was assessed in the present study reported that he left University and started to cultivate rice. The mean age of rice producers in Fogera district was more or less corresponding with the national average age. This implies rice cultivation is undertaken by a relatively young segment of the population in the region/district and the country in general. 
In Ethiopia, the national average age of rice producers was 40 years while the average age across the rice production systems was 40 years for irrigated, 44 years for upland and 40 years for lowland rainfed (Minilik et al 2013).

\subsubsection{Family Size}

In this study, the same figure was found with the national average family size, 5 persons in rice producing households in Fogera. The national average family size of rice producing households was 5 persons and the average rice producing household size across the regions was $6,5,6,11,5$, and 5 persons for Tigray, Amhara, Oromia, Somali, Benishangul Gumuz, and SNNPR, respectively (Minilik et al 2013).

It has been shown that that the size of family might be an important socio-economic characteristic since it determines the allocation of family labor and also regulates the extent to which a household is able to respond to innovative changes and re-scaling of production (Fashola et al 2007, Tamiyu et al 2009). Besides, family size has its own contribution to rice production particularly in developing countries where lack of machineries and modern technologies are common (Onumadu, et al 2014).

\subsubsection{Variety Preference}

X.Jigina has good cooking quality to prepare the most common Ethiopian food ("Injeera"). Injeera prepared from X.Jigina has a lighter color and is soft, both characteristics being preferred by the farmers and other final rice consumers.

The results in the present study indicate that the majority of the farmers are influenced by grain color to choose their variety. However this does not mean grain color independently affects their variety preference, Grain color decisively influences the acceptance of the produce in the market since the white colored X.Jigina was more preferable than red Gumara. In terms of food quality there are two main reasons driving the choice of X.Jigina: firs of all, there is no culture to prepare red "Injeera" in Fogera and in the country in general and secondly, Injeera prepared with Gumara is harder than the one prepared with X.Jigina.

\subsubsection{Rice Farm and its Trends}

The average area of rice at national level was 0.74 and 0.76 hectares per rice producer in 2010 and 2013 (Minilik 2013). In this study the mean cultivated area of rice was 0.83 ha and 0.67 ha in the present and the past ten years ago respectively which approximately closer to the national average.

Generally, there was a trend of increasing area of rice cultivation by farmers in the study area as compared with over the last ten years ago. The result of this study concedes with the increasing trend of rice farms and production in the country.

\subsubsection{Application of Fertilizer}

There was a study conducted so far in the district fertilizer was not applied for rice production. However, due to yield reductions of their respective plot, farmers were starting application of fertilizer in recent years (Hagos 2014). In this study confirmed similarly there was no application of fertilizer ten years ago but all farmers use fertilizer in the present. The tremendous change of fertilizer application comes due to decreasing of yield performance which triggered by occurrence of disease and pest. Farmers complain about fertilizer related issues such as affordability and its availability in adequate quantity.

\section{CONCLUSION AND RECOMMENDATION}

In this study, it was realized that Gumara variety had no much acceptance by farmers in the Fogera district, Ethiopia because of some of its unsuitable characteristics fundamentally the grain color, market preference and cooking quality influence farmers and consumers. This result might indicate for breeders to give focus for variety improvement research and development activities to address the issues of color, yield, biomass, disease resistance and among other characteristics. Besides, the extension and research stakeholders shall to supply alternative seed of improved rice varieties for farmers to address this problem. It was also realized from this study farmers complained that there was a high shortage of seed supply particularly for recently released rice varieties. As rice is a new crop to the country, it needs a lot of research and development efforts to promote the rice sector and ensure food security. 
Over seventy percent of rice supplied from Fogerain the country. However, in the region all rice producing farmers depend on rainfed except very few farmers in upland areas rarely use supplementary irrigation when there is lack of water. The district is very close to the lake Tana which is the largest lake in the country, and this is a great opportunity for rice producing farmers in the district and the surrounding region to sustainably exploit the resource for irrigated rice production. The district is also bounded by rivers such as Eribb and Gumara which might be used as source of water for irrigated rice production. The respective governmental or non-governmental stakeholders might capitalize on these plenty of resources to use for rice irrigation to boost rice production in the region and promote rice sector in the country in general.

\section{REFERENCES}

[1] Alemu, D., Shiratori, K., 2011. Stakeholder Analysis in Rice Research and Development. Challenges and Opportunities of Rice in Ethiopian Agricultural Development.FRG II Project, Ethiopian Institute of Agricultural Research, 24-31.

[2] Asmelash, Y., 2014. Determinants of adoption of upland rice varieties in Fogera district, South Gondar, Ethiopia. Journal of Agricultural Extension and Rural Development 8(12), 332-338.

[3] Belayineh, T., Jember, T., 2017. Review On Adoption, Trend, Potential, And Constraints Of Rice Production To Livelihood In Ethiopia. International Journal of Research -Granthalaayah 5(6), 2394-3629.

[4] FAOSTAT, 2018. Food and Agriculture Data, Food and Agriculture Organization of the United Nations. http://www.fao.org/faostat/en/\#data/QC. (last visited 12.11.2018)

[5] Fashola, O. O.,Oladele, O. I., Alabi, M. O., Tologbonse, D., Wakatsuki, T., 2007. Socio-economic factors influencing the adoption of sawah rice production technology in Nigeria. Journal of Food Agriculture and Environment 5(1), 239-242

[6] Gebey, T., Berhe, K., Hoekstra, D., Alemu, B., 2012. Rice value chain development in Fogera woreda based on the IPMS experience. Nairobi, Kenya: International Livestock Research Institute, 2-22

[7] Hagos, A,.Zewudu, L,. 2015. Improved Rice Seed Production and Marketing: Challenges and Opportunities in the Case of Fogera District of Ethiopia, Journal of Agriculture and Environmental Sciences (JAES) 1(2)

[8] Hagos, Zewudu, L, 2014. Determinants of Improved Rice Varieties Adoption in Fogera District of Ethiopia. ScienceTechnol and Arts Research Journal 4 (1), 221-228

[9] Kebbede, G., Jacob, M. J., 1988. Drought, famine and the political economy of environmental degradation in Ethiopia. Geography, 73(1), 65-70.

[10] Minilik,T., Alemu, D., Kiyoshi, S., 2013. Socioeconomic characteristics of smallholder rice production in Ethiopia. Ethiopian Institute of Agricultural Research, Ethiopia. Research Report, 2-45

[11] Onumadu, F. N., Osahon, E. E., 2014. Socio-economic determinants of adoption of improved rice technology by farmers in Ayamelum local government area of Anambra State, Nigeria. International Journal of Scientific and Technology Research, 3(1), 308-314.

[12] Takele, A., 2017.Determinants of Rice Production and Marketing in low Producer Farmers: the Case of Fogera Districts, North-Western Ethiopia. International Journal of Environment, Agriculture and Biotechnology, 2(5).2534-2545.

[13] Tamiyu, S. A., Akintola, J. O., Rahji, M. A. Y., 2009. Technology adoption and productivity difference among growers of new rice for Africa in Savanna Zone of Nigeria. Tropicultura, 27(4), 193-197.

[14] Temesgen, Y., Tilahun, D., Belay, B., 2014. Production Expansion, Competitiveness and Comparative Advantage of Upland Rice Production: Case of Fogera and Libokemekem Plain in Ethiopia. The International Journal of Applied Economics and Finance, 8(2), 48-50.

Citation: Tegegne, Misganaw (M.S.c), Dr. Mathias Becker, "Assessment of Socio-Economic and Agronomic Characteristics Influencing Variety Choice in Rice Based Farming System in Fogera- Ethiopia" International Journal of Research Studies in Agricultural Sciences (IJRSAS), 2019; 5(12), pp. 27-34, http://dx.doi.org/10.20431/2454-6224.0512004

Copyright: () 2019 Authors. This is an open-access article distributed under the terms of the Creative Commons Attribution License, which permits unrestricted use, distribution, and reproduction in any medium, provided the original author and source are credited. 